\title{
Metabolite-Based Modification of Poly(L-lysine) for Improved Gene Delivery
}

Morgan A. Urello ${ }^{\dagger}$,Lucia Xiang ${ }^{\dagger}$, Raffaele Colombo ${ }^{\dagger}$,Alexander Ma ${ }^{\ddagger}$, Augustine Joseph ${ }^{*}$, Jonathan Boyd , Norman Peterson', Changshou Gao ${ }^{\dagger}$, Herren W $u^{\dagger}$, and R. James Christie ${ }^{\dagger *}$

${ }^{\dagger}$ Antibody Discovery and Protein Engineering, R\&D AstraZeneca, Gaithersburg MD, 20878

† SynChem, Inc. Elk Grove Village IL, 60007

† Translational Sciences, AstraZeneca Biopharmaceuticals R\&D, Gaithersburg MD, 20878

\section{SUPPORTING INFORMATION}

\section{Table of Contents}

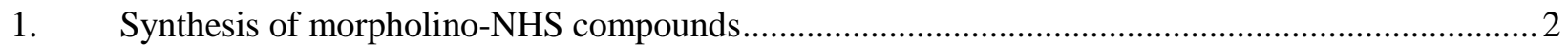

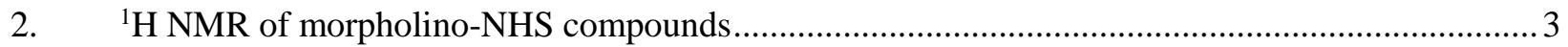

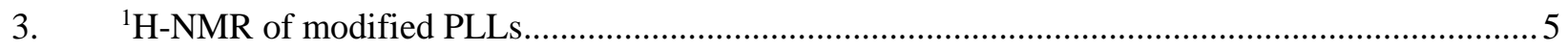

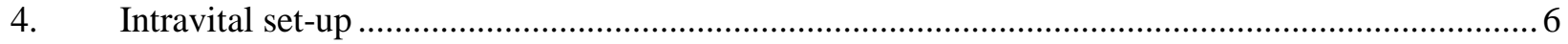

5. Overview of experiment to track $\mathrm{pH}$ in live cells ................................................................... 7

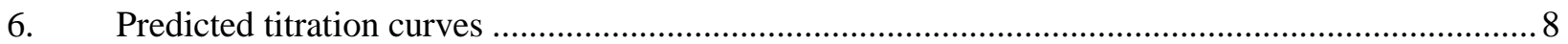

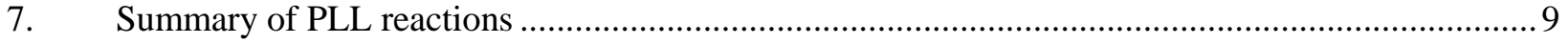

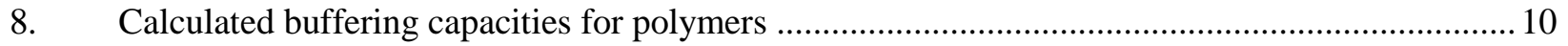

9. Colocalization of green and red signals in fluorescence microscopy studies ............................... 10

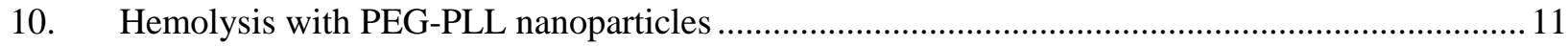

11. Representative DNA condensation analysis by gel electrophoresis for N:P optimization .............12

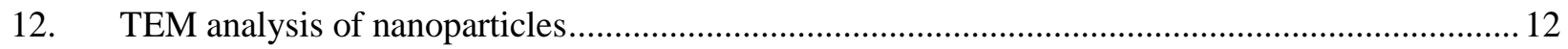

13. Stability of PEG-PLL nanoparticles with $>50 \%$ modification ............................................... 13

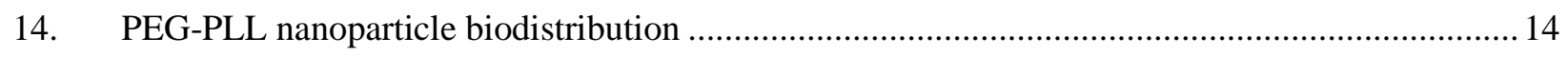

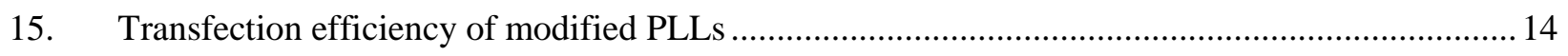

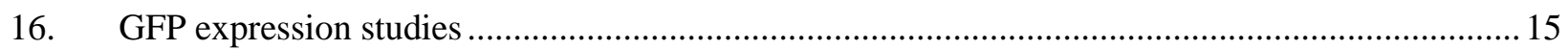




\section{Synthesis of morpholino-NHS compounds}

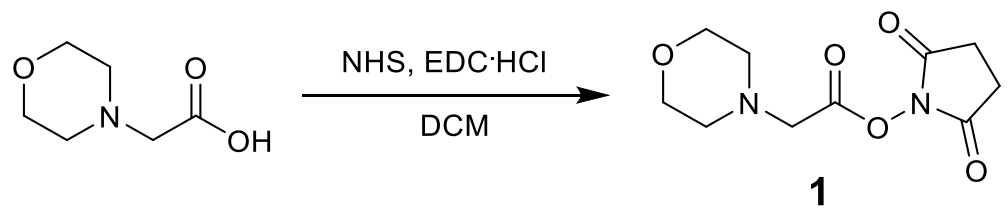

Scheme S1. Synthesis of morpholine - NHS ester 1

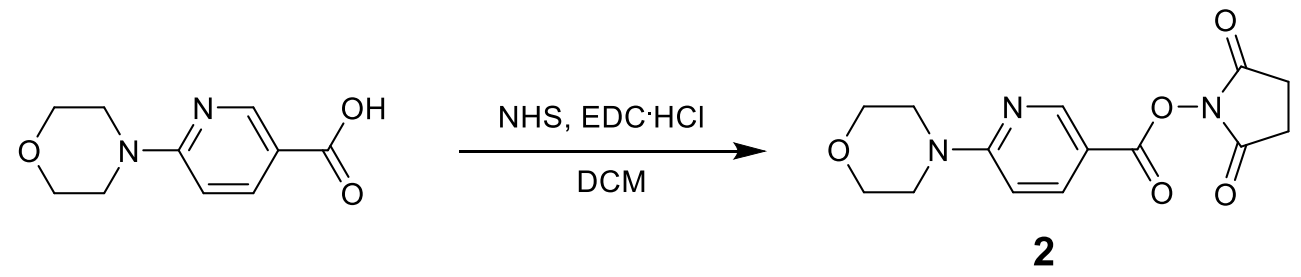

Scheme S2. Synthesis of morpholino-niacin-NHS modifier 2.

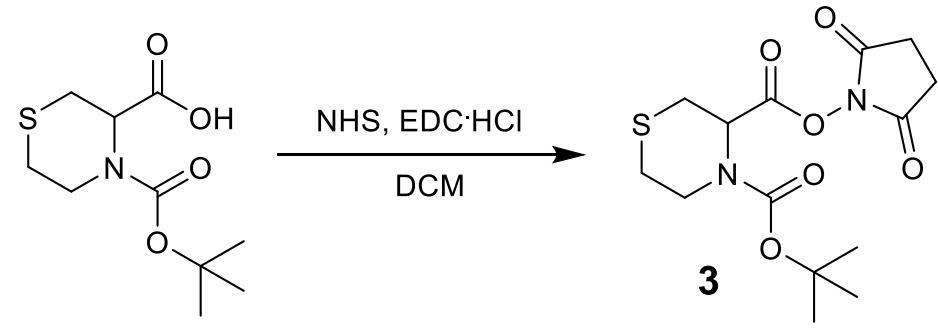

Scheme S3. Synthesis of thiomorpholine (boc) - NHS ester 3 


\section{2. ${ }^{1} \mathrm{H}$ NMR of morpholino-NHS compounds}

A
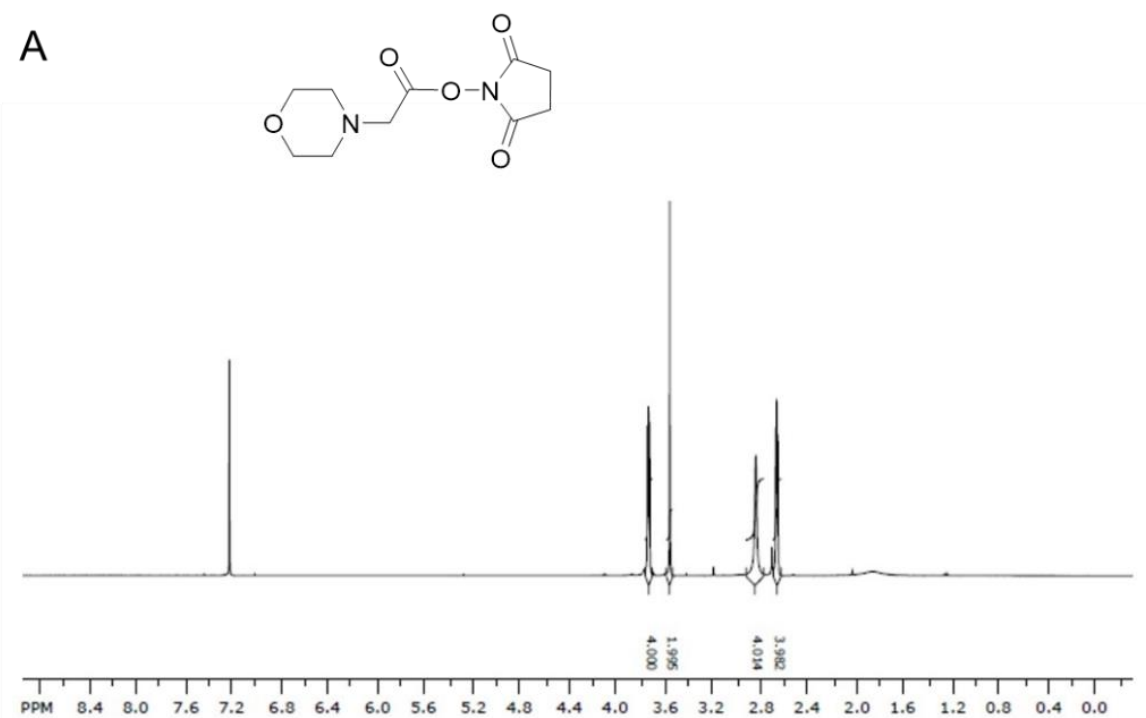

B

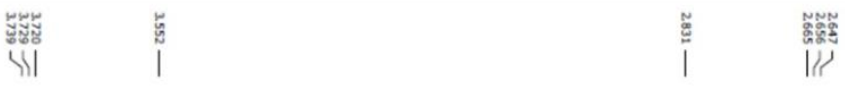

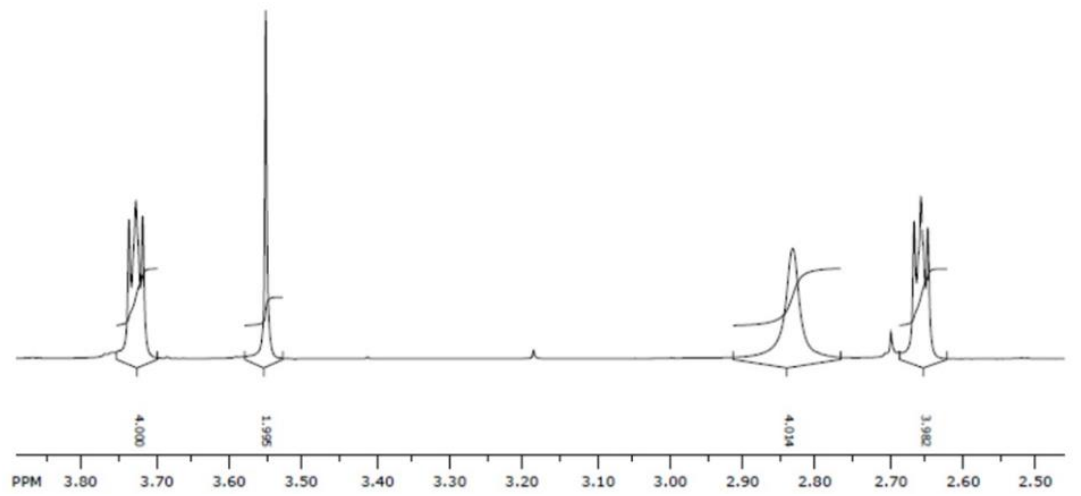

Figure S1. ${ }^{1} \mathrm{H}$ NMR of compound 1. A) full spectrum, B) 2.5-3.8 ppm zoom. 


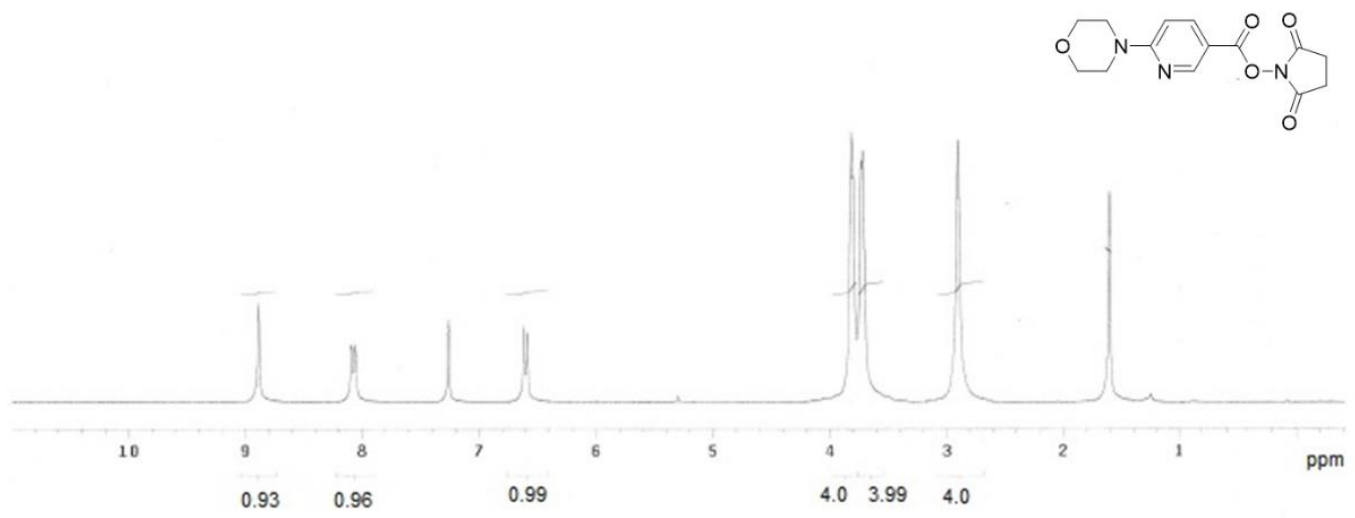

Figure S2. ${ }^{1} \mathrm{H}$ NMR of 2 recorded at $300 \mathrm{mHz}$ in $\mathrm{CDCl}_{3}$

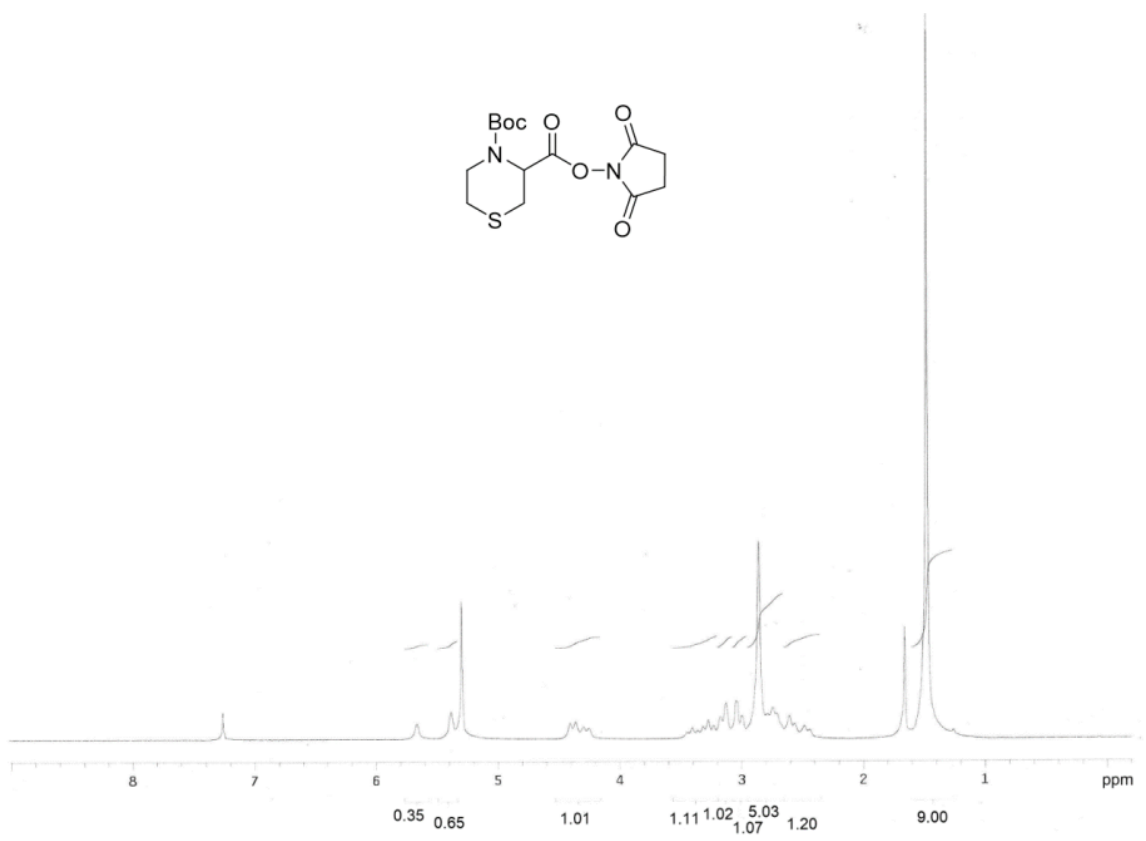

Figure S3. ${ }^{1} \mathrm{H}$ NMR of 3 recorded at $300 \mathrm{mHz}$ in $\mathrm{CDCl}_{3}$. 


\section{3. ${ }^{1}$ H-NMR of modified PLLs}
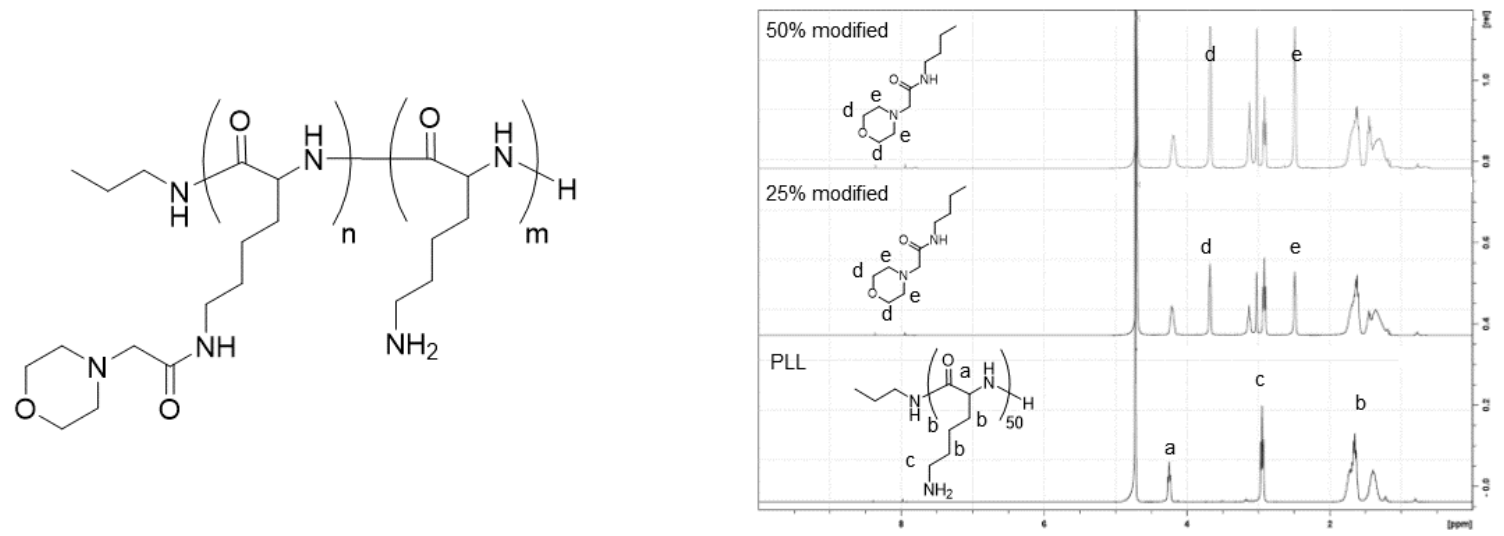

Figure S4. ${ }^{1} \mathrm{H}$ NMR of PLL modified with different amounts of compound 1 (M).
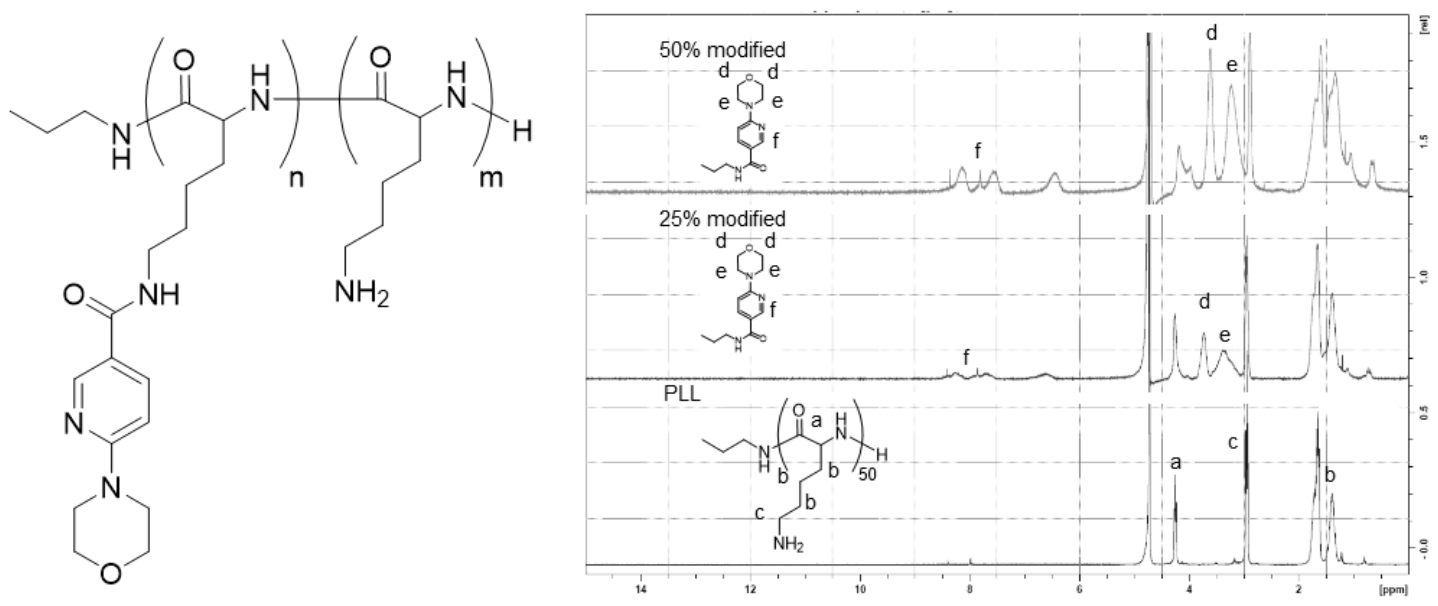

Figure S5. 1H NMR of PLL modified with different amounts of compound 2 (MN). 

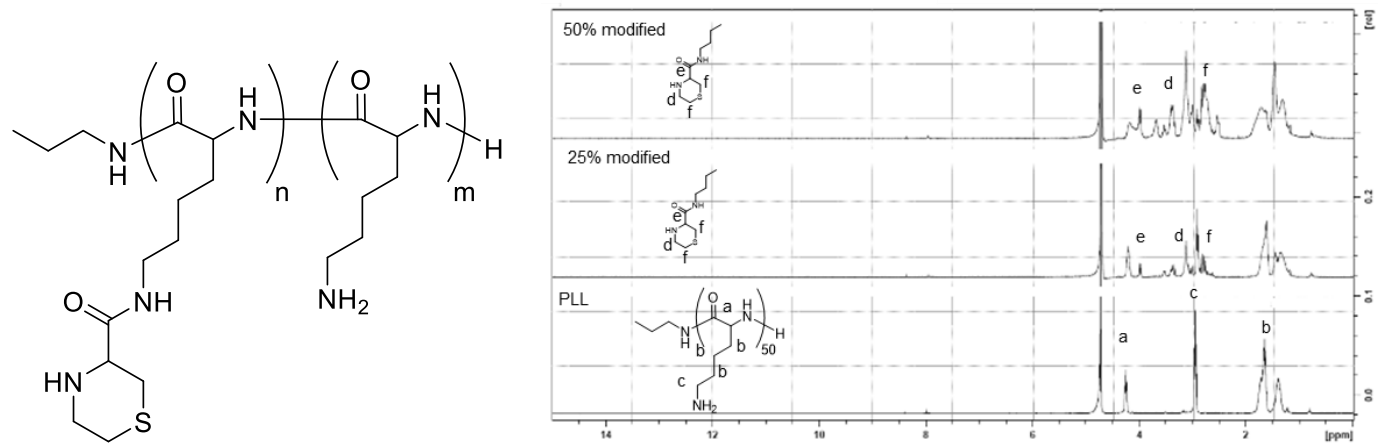

Figure S6. ${ }^{1} \mathrm{H}$ NMR of PLL modified with different amounts of compound 3 (TM).

\section{Intravital set-up}

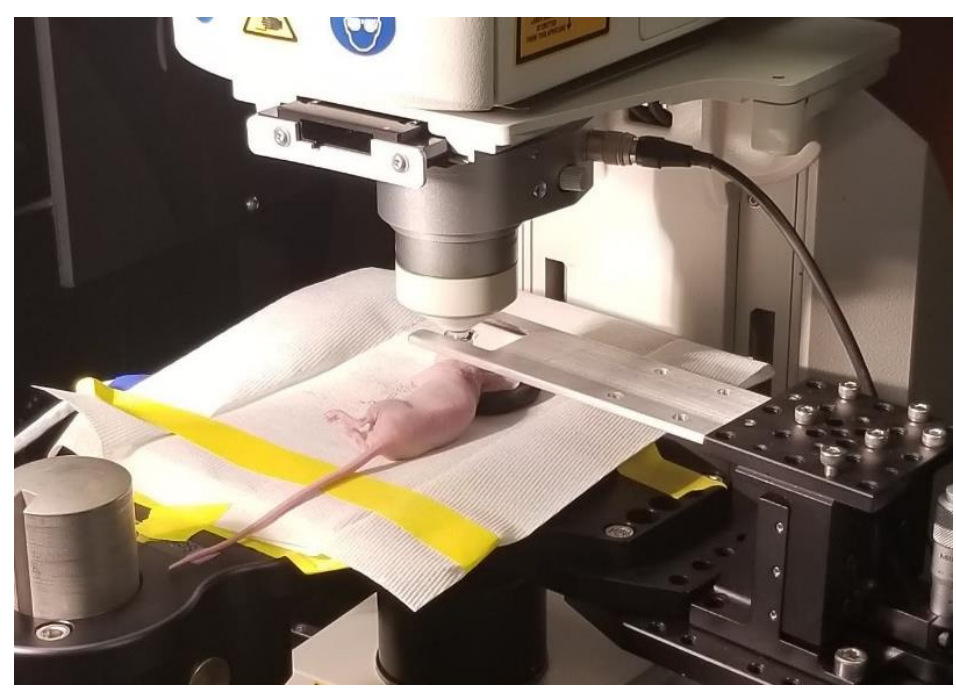

Figure S7. A custom slide holder was used to position the mouse ear for intravital imaging. 


\section{Overview of experiment to track $\mathrm{pH}$ in live cells}

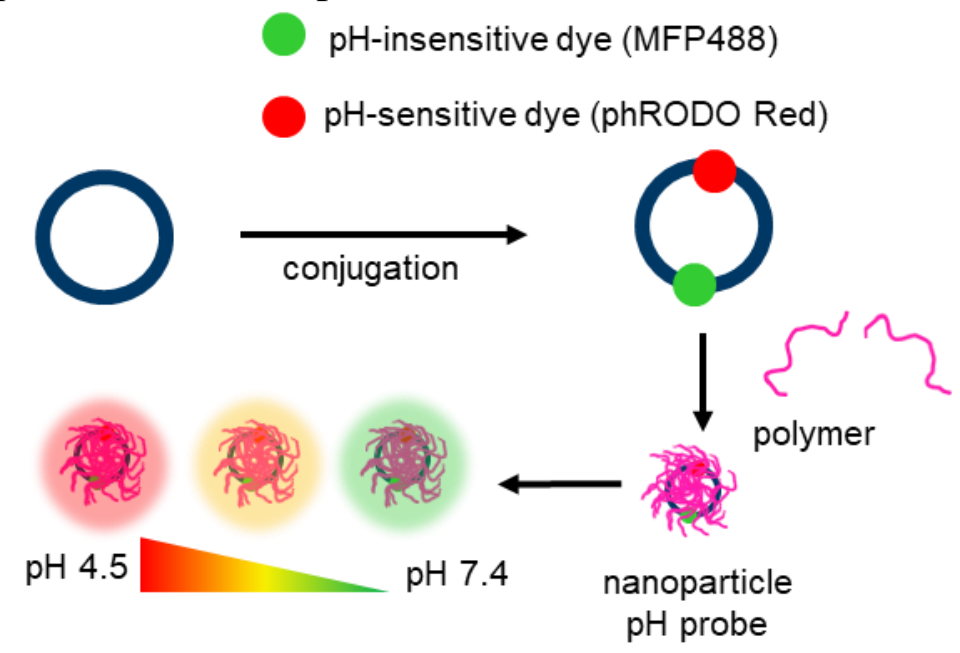

Figure S8. Overview of lysosomal buffering study in which pDNA was dual-labeled with MFP488 and phRODO Red in order to act as a pH probe in intracellular uptake studies. 


\section{Predicted titration curves}

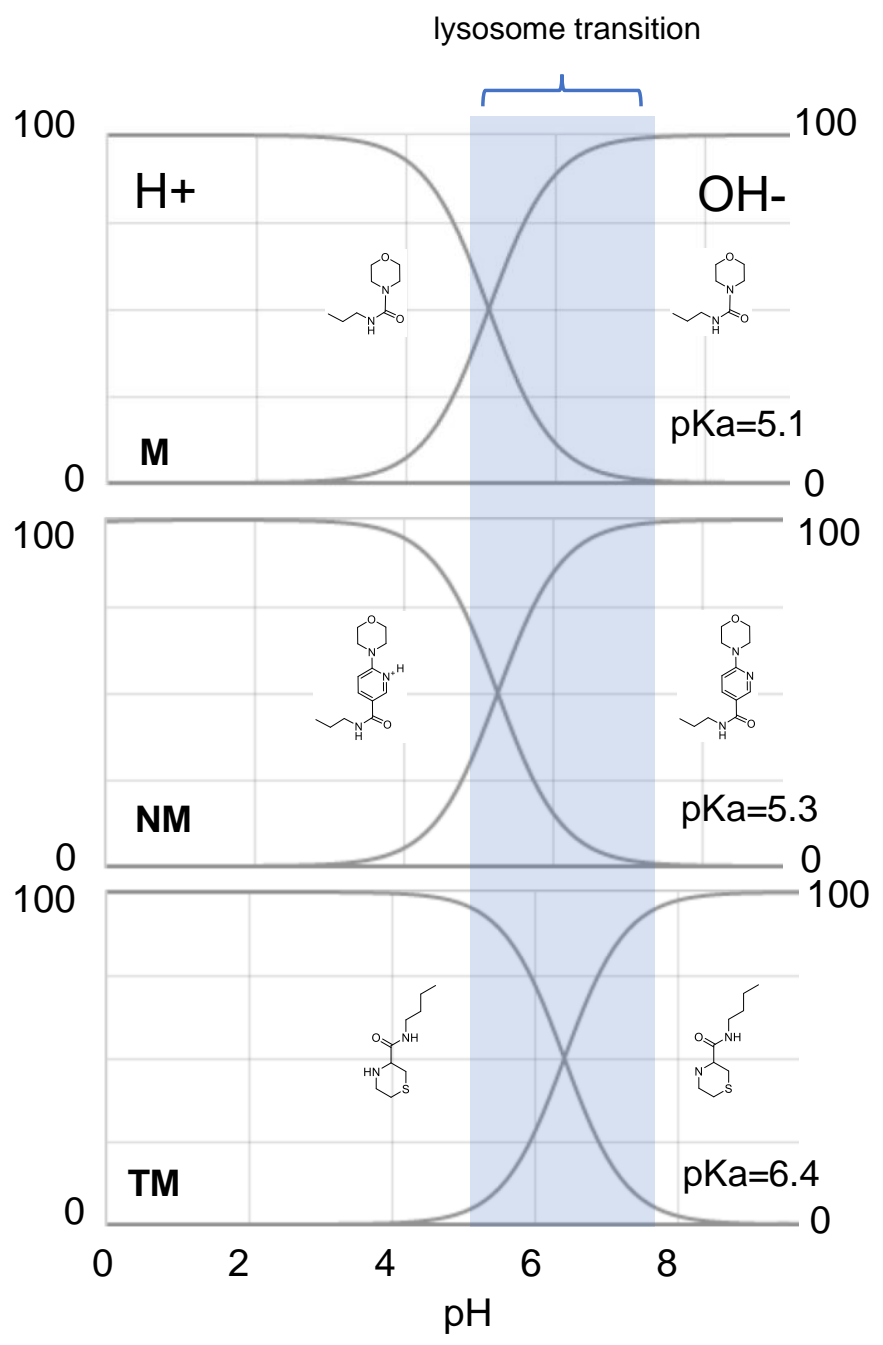

Figure S9. Titration curves estimated using ACD/ChemSketch (Advanced Chemistry Development Inc) software. 


\section{Summary of PLL reactions}

Table S1. Summary of PLL reactions

\begin{tabular}{cccccc}
\hline Entry & polymer & $\begin{array}{c}\text { Feed ratio } \\
\text { (moles NHS:moles } \\
\text { amine) }\end{array}$ & $\begin{array}{c}\text { Modified } \\
\text { lysines (\%) }\end{array}$ & $\begin{array}{c}\text { Modified } \\
\text { lysines }\end{array}$ & $\begin{array}{c}\text { Unmodified } \\
\text { lysines }\end{array}$ \\
\hline $\mathbf{1}$ & PLL (M) & 0.25 & 24 & 12 & 38 \\
\hline $\mathbf{2}$ & PLL (M) & 0.50 & 37 & 18.5 & 31.5 \\
\hline $\mathbf{3}$ & PLL (M) & 1 & 53 & 26.5 & 23.5 \\
\hline $\mathbf{4}$ & PLL (MN) & 0.25 & 24 & 12 & 38 \\
\hline $\mathbf{5}$ & PLL (MN) & 0.50 & 32 & 16 & 34 \\
\hline $\mathbf{6}$ & PLL (MN) & 1 & 51 & 25.5 & 24.5 \\
\hline $\mathbf{7}$ & PLL (TM) & 0.25 & 21 & 10.5 & 39.5 \\
\hline $\mathbf{8}$ & PLL (TM) & 0.50 & 39 & 19.5 & 30.5 \\
\hline $\mathbf{9}$ & PLL (TM) & 1 & 50 & 25 & 25 \\
\hline $\mathbf{1 0}$ & PEG-PLL (M) & 0.25 & 24 & 12 & 38 \\
\hline $\mathbf{1 2}$ & PEG-PLL (M) & 0.50 & 41 & 20.5 & 29.5 \\
\hline $\mathbf{1 3}$ & PEG-PLL (M) & 1 & 63 & 31.5 & 18.5 \\
\hline $\mathbf{1 4}$ & PEG-PLL (MN) & 0.25 & 24 & 12 & 38 \\
\hline $\mathbf{1 5}$ & PEG-PLL (MN) & 0.50 & 39 & 19.5 & 30.5 \\
\hline $\mathbf{1 6}$ & PEG-PLL (MN) & 1 & 65 & 32.5 & 17.5 \\
\hline $\mathbf{1 7}$ & PEG-PLL (TM) & 0.25 & 24 & 12 & 38 \\
\hline $\mathbf{1 8}$ & PEG-PLL (TM) & 0.50 & 33 & 16.5 & 33.5 \\
\hline $\mathbf{1 9}$ & PEG-PLL (TM) & 1 & 61 & 30.5 & 19.5 \\
\hline
\end{tabular}




\section{Calculated buffering capacities for polymers}

Table S2. Buffering properties of polymers

\begin{tabular}{lcccc}
\hline \multicolumn{1}{c}{ material } & $\begin{array}{c}\mathrm{HCl} \text { volume } \\
(\mu \mathrm{L})\end{array}$ & $\begin{array}{c}\mathrm{H}+ \\
(\mu \mathrm{moles})\end{array}$ & $\alpha_{7.4-4.5}$ & $\alpha_{11-4.5}$ \\
\hline PEG-PLL & 10 & 1 & 0.08 & 0.95 \\
PEG-PLL 41\% $(\mathrm{M})$ & 27.5 & 2.75 & 0.18 & 0.78 \\
PEG-PLL 39\% $(\mathrm{MN})$ & 67.5 & 6.75 & 0.44 & 1.00 \\
PEG-PLL 33\% $(\mathrm{TM})$ & 112.5 & 11.25 & 0.65 & 1.01 \\
PEI 25K & 40 & 4 & 0.29 & 0.9 \\
\hline
\end{tabular}

9. Colocalization of green and red signals in fluorescence microscopy studies

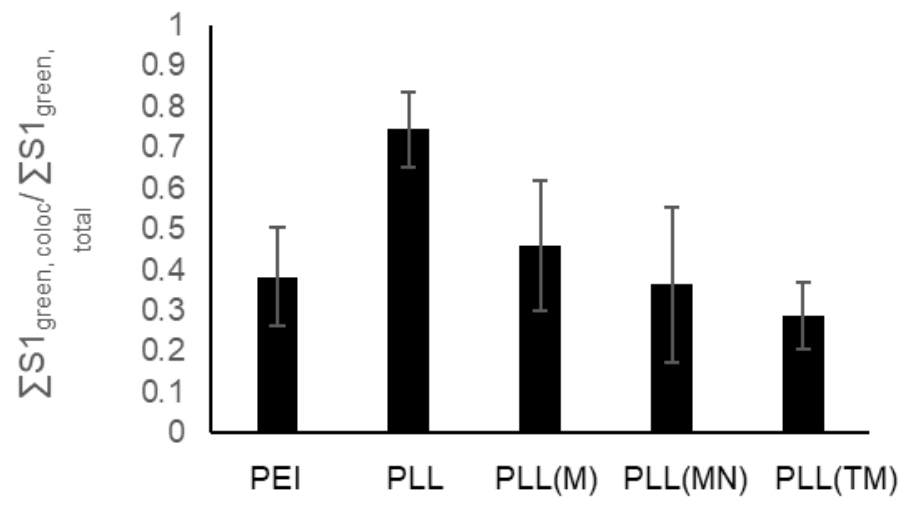

Figure S10. Fluorescence confocal microscopy study of pDNA labelled with $\mathrm{pH}$ insensitive (MFP488, green) and pH-sensitive (pHrodo, red) dyes. Colocalization of red and green channels was defined by the Manders coefficient $=\sum \mathrm{S} 1_{\text {green, }}$ coloc $/ \sum \mathrm{S} 1_{\text {green, }}$ total per cell. 


\section{Hemolysis with PEG-PLL nanoparticles}

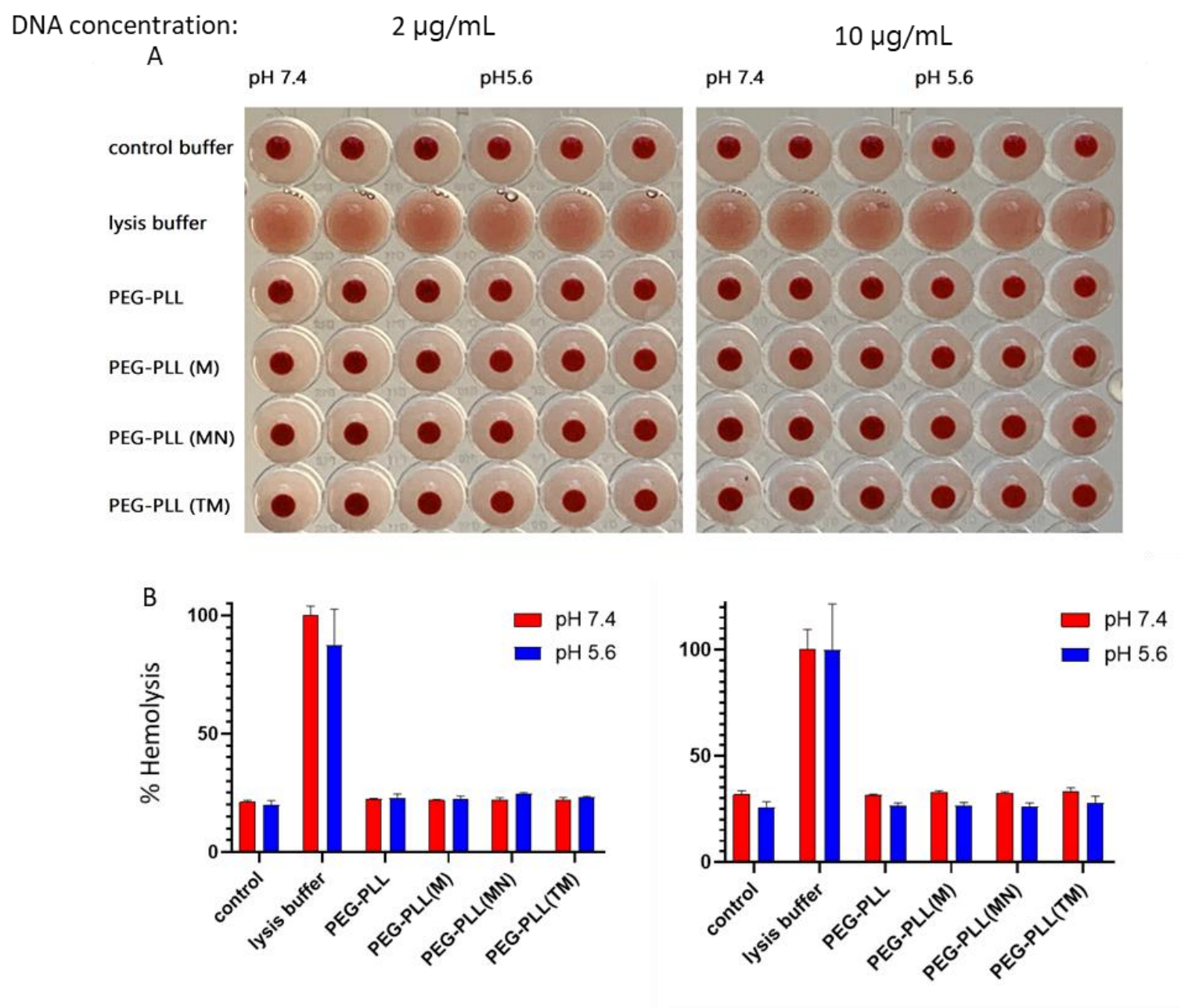

Figure S11. Hemolysis assay with PEG-PLL nanoparticles. (A) Representative images of RBC pellet post-treatment and (B) Quantified hemolytic activity. 
11. Representative DNA condensation analysis by gel electrophoresis for N:P optimization PEG-PLL $\quad 25 \%$ (MN) $\quad 50 \%$ (MN)

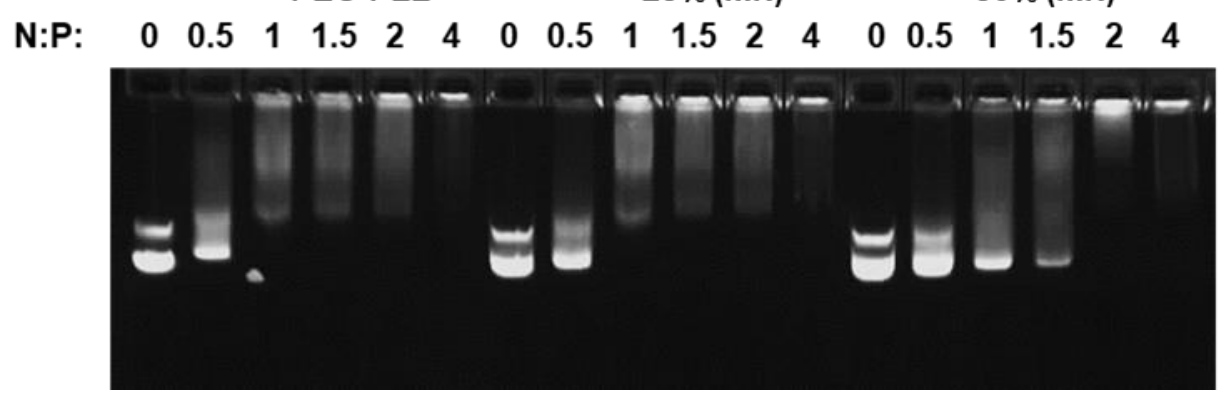

Figure S12. Nanoparticle formulations prepared with identical amounts of pDNA and different amounts of polymer were run through an ethidium bromide stained agarose gel to determine the amount of polymer or N:P needed for pDNA condensation.

\section{TEM analysis of nanoparticles}

A

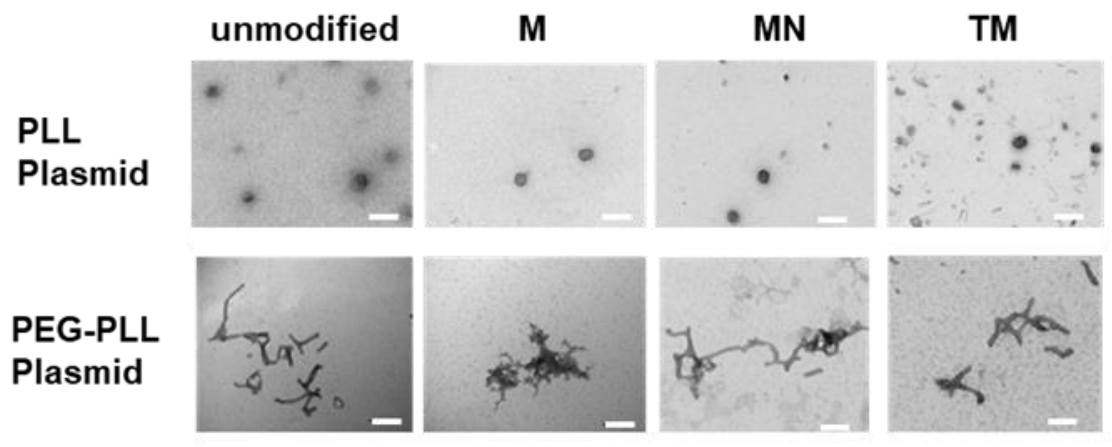

B

\begin{tabular}{|c|cc|ccc|cc|}
\hline & \multicolumn{3}{|c|}{ Sphere } & \multicolumn{3}{c|}{ Rod } & \multicolumn{2}{c|}{ Toroid } \\
\cline { 2 - 8 } & $\begin{array}{c}\text { Frequency } \\
(\%)\end{array}$ & $\begin{array}{c}\text { Diameter } \\
(\mathrm{nm})\end{array}$ & $\begin{array}{c}\text { Frequency } \\
(\%)\end{array}$ & $\begin{array}{c}\text { Diameter } \\
(\mathrm{nm})\end{array}$ & $\begin{array}{c}\text { Length } \\
(\mathrm{nm})\end{array}$ & $\begin{array}{c}\text { Frequency } \\
(\%)\end{array}$ & $\begin{array}{c}\text { Diameter } \\
(\mathrm{nm})\end{array}$ \\
\hline PLL & 90 & $40 \pm 7$ & 10 & $14 \pm 9$ & $88 \pm 70$ & 0 & NA \\
PLL (M) & 80 & $42 \pm 9$ & 10 & $16 \pm 6$ & $280 \pm 112$ & 10 & $60 \pm 7$ \\
PLL (MN) & 100 & $43 \pm 10$ & 0 & NA & NA & 0 & NA \\
PLL (TM) & 80 & $52 \pm 14$ & 10 & $15 \pm 6$ & $150 \pm 41$ & 10 & $53 \pm 8$ \\
PEG-PLL & 0 & NA & 100 & $12 \pm 4$ & $101 \pm 29$ & 0 & NA \\
PEG-PLL (M) & 0 & NA & 100 & $10 \pm 3$ & $27 \pm 22$ & 0 & NA \\
PEG-PLL (MN) & 0 & NA & 100 & $11 \pm 5$ & $70 \pm 63$ & 0 & NA \\
PEG-PLL (TM) & 0 & NA & 100 & $10 \pm 2$ & $66 \pm 45$ & 0 & NA \\
\hline
\end{tabular}

Figure S13. Visualization (A) and quantification (B) of nanoparticle morphology by transmission electron microscopy (TEM). Scalebars in each image represent $100 \mathrm{~nm}$. 


\section{Stability of PEG-PLL nanoparticles with $>\mathbf{5 0} \%$ modification}

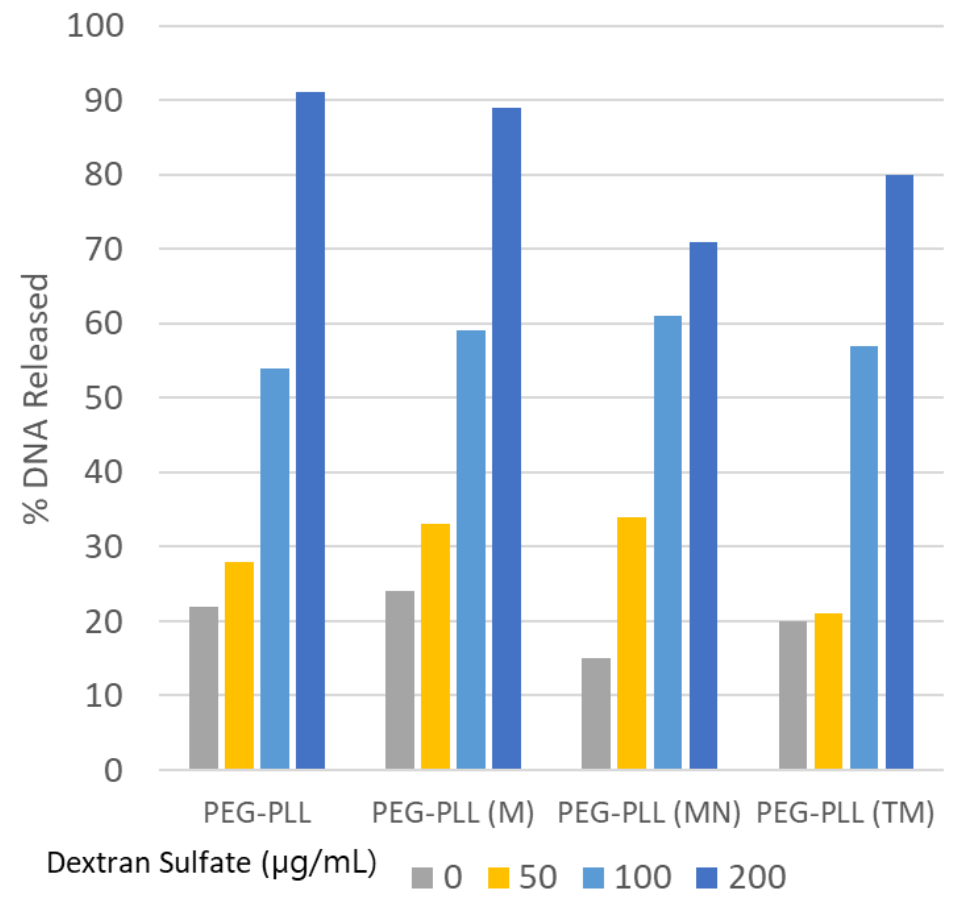

Figure S14. Stability assessment of nanoparticles towards anionic displacement of pDNA by dextran sulfate (DS) and within circulation. Gel-electrophoresis of nanoparticles prepared with PEG-PLL and modified PEG-PLL ( $\sim 50 \%$ modified amines) following exposure to different concentrations of DS and incubation at $37{ }^{\circ} \mathrm{C}$ for $1 \mathrm{~h}$. Gels were stained with ethidium bromide to visualize pDNA. Quantification of intact nanoparticles at different concentrations of dextran sulfate. Band intensities of pDNA and nanoparticle-bound DNA was determined using Image-J. 
14. PEG-PLL nanoparticle biodistribution

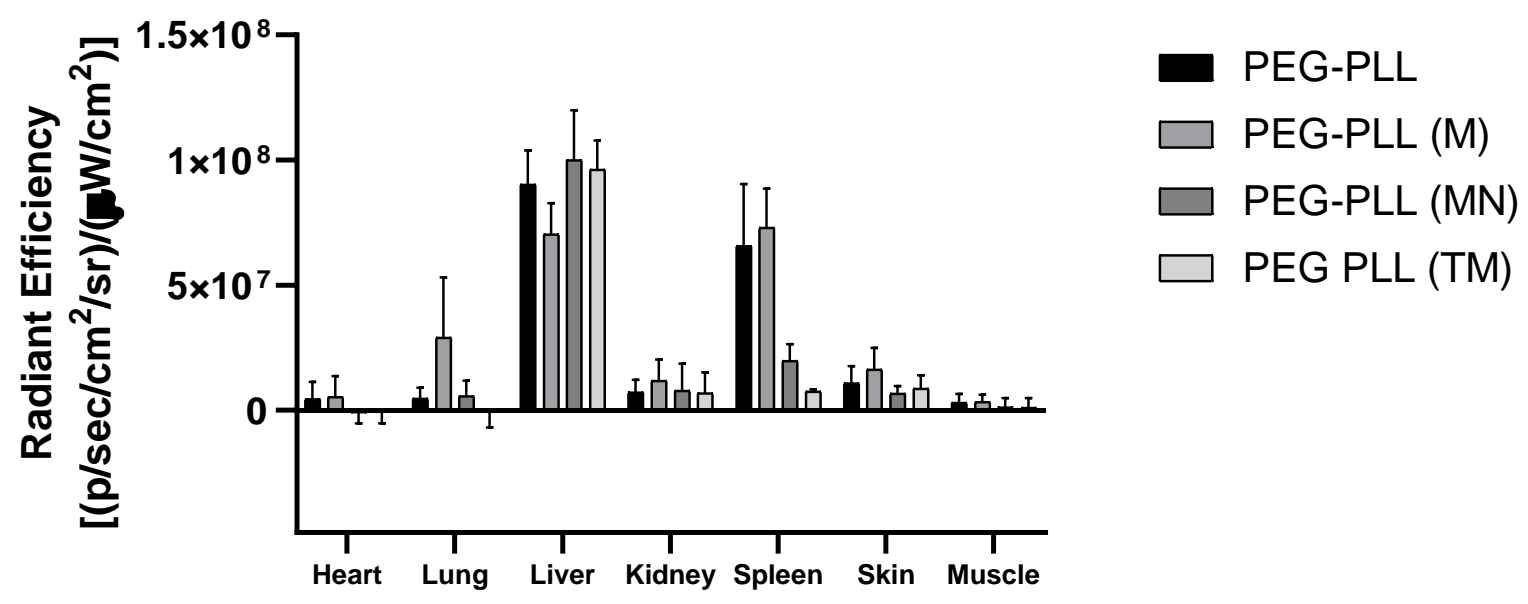

Figure S15. Biodistribution of nanoparticles.

15. Transfection efficiency of modified PLLs
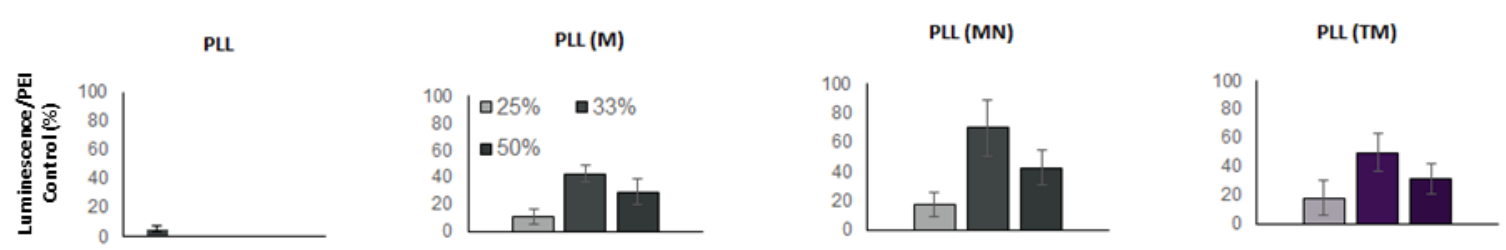

Figure S16. The degree of modification was optimized on PLL in a series of in vitro transfections in H1299 cells in serum supplemented media (10\% FBS). The \% was consistently found to be around $33 \%$ for each modifier. 


\section{GFP expression studies}

A

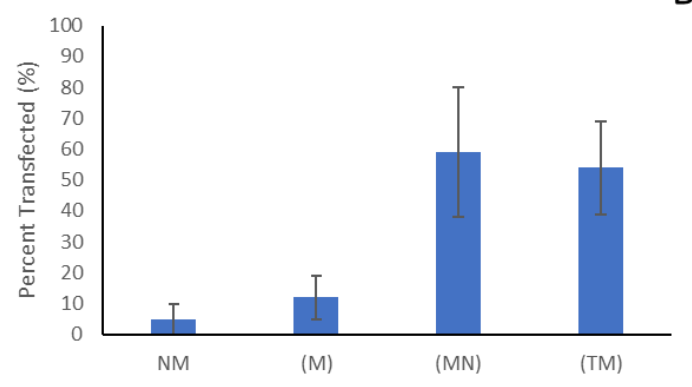

B

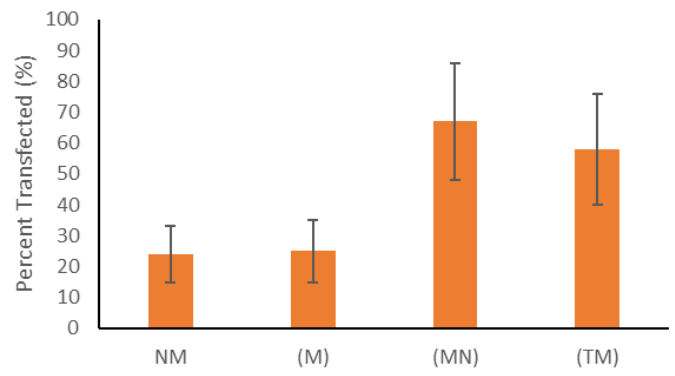

Figure S17. Transfection of H1299 cells. Cells were treated with nanoparticles encapsulating plasmid GFP DNA prepared with A) PLL in OPTI-MEM or B) PEG-PLL in medium supplemented with $10 \%$ FBS and $100 \mu \mathrm{M}$ chloroquine. All modified PLLs had approximately a $30 \%$ modified lysines. \% cell transfected was quantified $48 \mathrm{~h}$ post transfection using an Inucyte ${ }^{\circledR}$ S3 Live-Cell Analysis System. The software was used to calculate the cell confluence and green area in 5 locations in 4 different wells. The number of cells was estimated by dividing the area by the average cell area $(\mathrm{n} \sim 152$ cells/image) and the percent of cells transfected was calculated by dividing the estimated number of green cells by total cell. 